\title{
CALCULATION OF MAXIMUM WATER CONTENT IN VARIOUS NATURAL GASES BY USING MODIFIED PENG-ROBINSON EQUATION OF STATE
}

During the expansion of natural gas in the pipeline, the gas cools down due to the Joule-Thomson effect and due to the interaction between pipeline system and its surroundings to the conditions at which gas is saturated by water vapors, and gas is not able to keep excess humidity and its condensation and hydrate formation will occur. For that reason it is necessary to identify the critical parts of the pipeline systems, maximum water content in the gas, to choose appropriate physical model, and apply appropriate solutions which also will considerably influence energy consumption requirements. For the physical model development, method based on equality of fugacity concept with modified PengRobinson equation of state and Rachford-Rice appropriate solution algorithm are used to develop the model estimating the water content in equilibrium with natural gas. The results of the presented method are compared with selected experimental data from the literature.

Keywords: Natural gas, water content, phase equilibrium, gas hydrate, equation of state

\author{
Nomenclature: \\ fugacity, $\mathrm{Pa}$ \\ $k_{i j}(T)$ temperature dependent binary interaction parameter of PR \\ EoS \\ $k_{i j, 0} \quad$ binary interaction parameter of PR EoS \\ $k_{i j, 1} \quad$ binary interaction parameter of PR EoS \\ $p$ pressure, $\mathrm{Pa}$ \\ $T$ temperature, $\mathrm{K}$ \\ $x \quad$ set of liquid phase mole fractions \\ $y \quad$ set of vapor phase mole fractions \\ $\alpha\left(T_{r}\right)$ dimensionless temperature dependent function of PR EoS \\ $\phi \quad$ fugacity coefficient \\ $L \quad$ superscript denot as liquid \\ $V \quad$ superscript denot as vapor \\ sat superscript, saturated vapor \\ cal subscript, calculated property \\ exp subscript, experimental property \\ $i, j \quad$ subscript, molecular species \\ id subscript, ideal gas \\ initial subscript, initial estimate for calculation \\ $r \quad$ subscript, reduced parameter (temperature, pressure) \\ $w \quad$ subscript denotes water
}

\section{Introduction}

The pressure of natural gas (NG) for final consumptions declines during the transmission and distribution to the values that are utilized in medium and low pressure distribution systems. NG contains certain amount of water that is expressed by water dew point temperature replenished with respective pressure. During the expansion of NG in the pipeline, the gas cools down due to the Joule-Thomson effect and due to the interaction between pipeline (and pipeline system equipments) and its surroundings (heat transfer processes) to the conditions at which different phase formation as water liquid, condensates and other solid materials (hydrates) might occur [1]. NG hydrates are crystalline solids composed of the water and the gas. The gas molecules (guest) are trapped in water cavities (host) that are composed of hydrogen-bonded water molecules [2]. Typical NG hydrate molecules include methane, ethane, propane, and carbon dioxide. Both hydrates and liquid slugs are damaging the gas pipeline system operation by corrosion, erosion, clogging and the mechanical stress to the system [3].

To avoid these problems, expensive dehydratation units, heating units, inhibitors units, etc., have been installed by natural gas companies. The design and cost of these installations depend on the exact knowledge of the water content at the dew point (contractually established). Though given water dew point is contracted, during NG transmission and distribution can be worsened mainly by new or mended pipelines. For that reason it is necessary to continue in developing new models for better identification of the critical points (water liquid or hydrate formation) in the gas pipeline systems.

Experience from industry have exposed that the maximum level of water content in vapor phase is bigger at higher pressures than the value that comes from the ideal gas model vapor-liquid equilib-

\footnotetext{
* Jan Rajzinger

Department of Thermal Power Engineering, Bratislava, Slovakia, Faculty of Mechanical Engineering, Slovak University of Technology in Bratislava, E-mail: jan.rajzinger@stuba.sk
} 
rium calculation. In order to solve the problem and to approach the real behavior of water-gas system it is necessary to use more complicated calculation that has to be numerically counted. PengRobinson equation of state (PR EoS) is by far the most popular cubic EoS that is used in the gas and oil industry nowadays. This equation is used to calculate the properties of pure compounds and, more importantly, binary and multicomponent mixtures including both low and high pressure vapor-liquid equilibrium [4], [5]. Calculation of water content is complicated due to non-ideal behavior of water and NG. For that reason, it is impossible to simulate interaction correctly with the normally used PR EoS. Therefore the modified PR EoS is used to calculate species fugacities in both phases (liquid and vapor), of course with the composition and compressibility appropriate to each phase.

This article presents the method for NG maximum water content calculations based on equality of fugacity concept with following presented methods which are also compared with selected experimental data from the literature:

- Ideal gas model with ANSI S1.26-1995 equation (The American National Standard Institute) for water saturated pressure calculations.

- Standard PR EoS without modifications.

- Modified PR EoS using 'Chapoy' modification.

- Modified PR EoS using GERG water model published as part of the ISO 18453, proposed by the European Gas Research Group GERG (Group Européen de Recherche Gazière).

Selected natural gases from practice, $100 \%$ methane and called "Russian NG", "Norwegian NG-type H" and "Norwegian NG-type L" are compared from maximum water content point of view at different pressures and temperatures ranges.

\section{Methods and models}

Gibbs theory showed that at thermodynamics equilibrium the pressure, temperature and fugacity (or chemical potential) of each component are the same for each coexisting phase. The starting point for vapor-liquid equilibrium is the equality of fugacities of each species in each phase, that is:

$$
f_{i}^{V}(T, p, y)=f_{i}^{L}(T, p, x) \quad(\mathrm{Pa})
$$

Equation (1) represents the starting point for any phase equilibrium calculation. However, the basic problem in this equation is to relate these fugacities to mixture composition. The fugacity of a component in a mixture depends on the temperature, pressure and composition of that mixture. Therefore to relate fugacities to temperature, pressure, and mole fraction, it is very useful to introduce the vapor and liquid-phase fugacity coefficient [6]:

$$
\phi_{i}^{V}(T, p, y)=\frac{f_{i}^{V}(T, p, y)}{y_{i} p}=\frac{f_{i}^{L}(T, p, x)}{x_{i} p}=\phi_{i}^{L}(T, p, x)(-)(2)
$$

Phase equilibrium calculations with equation of state are iterative and in this case the isothermal flash calculation is used [6].
The flash method is the type of calculation where the objective is to calculate the amount of phases present in an equilibrium mixture and to determine the composition of the coexisting phases. The temperature, pressure, and initial compositions are the input parameters. The objective function is solved by using Rachford-Rice algorithm. Then it uses the Newton-Rapson method for the correction steps.

\subsection{Ideal gas model for vapor-liquid equilibrium calculation}

The following simplifications are used for ideal gas model in terms of vapor-liquid equilibrium calculations:

- It is assumed that gases are not very well soluble in water, so solubility of gases in water is negligible and then liquid phase contains only clean liquid water.

- The gas impact on fugacity in liquid phase is neglecting.

- The total pressure is not very different from water saturated vapor pressure.

When the following simplifications are applied into Equation (1), the simple equation for calculation of maximum water content $y_{w, i d}$ in vapor phase is in the form:

$$
y_{w, i d}=\frac{p_{w}^{s a t}}{p}(-)
$$

For water saturated pressure calculations is used ANSI S1.261995 equation attributed to the World Meteorological Association [7]:

$$
\begin{aligned}
& \log _{10}\left(p^{s a t}\right)=10.79586\left[1-\left(\frac{273.16}{T}\right)\right]- \\
& -5.02808 \log _{10}\left(\frac{T}{273.16}\right)+ \\
& +1.50474 \times 10^{-4}\left\{1-10^{-8.29692}\left[\left(\frac{T}{273.16}\right)-1\right]\right\}+\quad(\text { atm })(4) \\
& +4.2873 \times 10^{-4}\left\{-1+10^{4.76955}\left[1-\left(\frac{T}{273.16}\right)\right]\right\}- \\
& -2.2195983
\end{aligned}
$$

This equation is said to have an uncertainty of $0.04 \%$ for temperature range $233<T<273 \mathrm{~K}$ and of $0.06 \%$ for $T>273 \mathrm{~K}$.

\subsection{Peng-Robinson equation of state}

The PR EoS provides a mathematical relation between the temperature, pressure, and molar volume $V$ of a pure fluid [6]. Various improvements of this equation are available in literature [8], [9], [10].

To have an accurate representation of vapor pressures of pure compounds a new energy term $\alpha\left(T_{r}\right)$ is proposed for modified PR EoS ('Chapoy' model) [11]: 


$$
\begin{aligned}
& \alpha\left(T_{r}\right)=\exp \left[c_{1}\left(1-\sqrt{T_{r}}\right)\right] \times \\
& \times\left[1+c_{2}\left(1-\sqrt{T_{r}}\right)^{2}+c_{3}\left(1-\sqrt{T_{r}}\right)^{3}\right]^{2}
\end{aligned}
$$

where $c_{1}, c_{2}$, and $c_{3}$ are new three adjustable parameters correlated as a functions of the acentric factor:

$$
\begin{aligned}
& c_{1}=1.3569 \omega^{2}+0.9957 \omega+0.4077 \\
& c_{2}=11.2986 \omega^{2}+3.5590 \omega+0.1146 \\
& c_{3}=11.7802 \omega^{2}+3.8901 \omega+0.5033
\end{aligned}
$$

Detailed applications ranges and limitations of this modified PR EoS are published only for prediction of water vapor pressure [11].

Modified Peng-Robinson EoS (GERG-model), in order to ensure an accurate calculation of water vapor pressure above ice and liquid, the following energy term $\alpha(\operatorname{Tr})$ is used for water [9]:

$$
\begin{aligned}
& \alpha\left(T_{r}\right)=\left[1+A_{1}\left(1-\sqrt{T_{r}}\right)+\right. \\
& \left.+A_{2}\left(1-\sqrt{T_{r}}\right)+A_{3}\left(1-\sqrt{T_{r}}\right)^{4}\right]^{2}
\end{aligned}
$$

where the new energy term in Equation (29) is by temperature ranges divided into two parts with $A_{1}, A_{2}$ and $A_{3}$ coefficients, see [8]. Finally, for the binary systems water/methane, water/ethane, water/carbon dioxide, modified Peng-Robinson EoS (GERG-model) introduces temperature-dependent on the interaction of parame- ters to obtain a satisfactory description of the vapor-liquid equilibrium, see [9]:

$$
k_{i j}(T)=k_{i j, 0}+k_{i j, 1}\left(\frac{T}{273.15}-1\right)
$$

The parameters in Equation (30) of the modified PR EoS, based on GERG model, are Tailor-made specifically for the water content calculations in NG where the solid phase is treated as a 'pseudo' liquid phase. The GERG model with PR EoS has a range of application from $0.5 \mathrm{MPa}$ to $10 \mathrm{MPa}$ and from $258 \mathrm{~K}$ to $278 \mathrm{~K}$ with defined accuracy, and "applicable" working range 0.1 - $30 \mathrm{MPa}$ and $223-313 \mathrm{~K}$ with unknown accuracy in the extra range. Detailed applications ranges and limitations of this GERG modified PR EoS and binary interaction parameters for other combinations of gases as well as the critical component properties are available in the literature [9], [10].

\section{Results}

Compositions of selected gas mixtures are showed in Table 1. Comparing the results of calculations from different methods used for determination of maximal water content in the gas of the methane-water system are together with the comparison of exper-

\begin{tabular}{|c|c|c|c|c|c|c|c|}
\hline \multirow{3}{*}{$\begin{array}{l}\text { Component } \\
\text { name }\end{array}$} & $\mathrm{NG} n^{\circ} 1$ & $\mathrm{NG} n^{\circ} 2$ & $\mathrm{NG} n^{\circ} 3$ & $\mathrm{NG} n^{\circ} 4$ & $N G n^{\circ} 5$ & $\mathrm{NG} n^{\circ} 6$ & $\mathrm{NG} n^{\circ} 7$ \\
\hline & Methane & $\begin{array}{l}\text { Laboratory } \\
\text { synthetic gas }\end{array}$ & $\begin{array}{c}\text { Laboratory } \\
\text { synthetic gas }\end{array}$ & $\begin{array}{l}\text { Laboratory } \\
\text { synthetic gas }\end{array}$ & $\begin{array}{l}\text { Russian (May } \\
\text { 2012) }\end{array}$ & $\begin{array}{l}\text { Norwegian- } \\
\text { Type H }\end{array}$ & $\begin{array}{l}\text { Norwegian- } \\
\text { Type L }\end{array}$ \\
\hline & \multicolumn{7}{|c|}{ Composition [mol \%.] } \\
\hline methane & 100.0000 & 94.0000 & 89.0000 & 84.4000 & 96.2450 & 84.4230 & 82.6570 \\
\hline ethane & - & 4.0000 & 7.0000 & 10.0000 & 1.8310 & 8.8540 & 3.4500 \\
\hline propane & - & - & - & 4.0000 & 0.5360 & 3.1700 & 0.7460 \\
\hline iso-butane & - & - & - & 0.6000 & 0.0750 & 0.3420 & 0.1026 \\
\hline n-butane & - & 2.0000 & 4.0000 & 1.0000 & 0.0840 & 0.6523 & 0.1598 \\
\hline iso-pentane & - & - & - & - & 0.0180 & 0.0912 & 0.0318 \\
\hline n-pentane & - & - & - & - & 0.0130 & 0.0870 & 0.0231 \\
\hline n-hexane & - & - & - & - & 0.0200 & 0.0293 & 0.0337 \\
\hline n-heptane & - & - & - & - & - & 0.0051 & 0.0150 \\
\hline n-octane & - & - & - & - & - & 0.0010 & 0.0050 \\
\hline hydrogen & - & - & - & - & - & 0.0020 & - \\
\hline helium & - & - & - & - & - & 0.0031 & - \\
\hline nitrogen & - & - & - & - & 0.8690 & 0.4210 & 11.6950 \\
\hline carbon dioxide & - & - & - & - & 0.3090 & 1.9190 & 1.0810 \\
\hline
\end{tabular}
imental values defined in Fig. 1.

Results prove that the maximal water content of methane-water system is always higher in the reality than in the ideal gas model. That means that gas is capable to keep much more water amount in the form of water vapors than it is presented in the results from

Compositions of selected natural gases [1]

Table 1 
the ideal gas model. The tendency of deviations of calculated figures from the experimental values of maximal water content in the gas is growing with the increasing temperature and pressure. At the pressure $3.34 \mathrm{MPa}$ and temperature $250.95 \leq \mathrm{T} \leq 288.15 \mathrm{~K}$ the ideal gas model gives better results than standard PR EoS, see Fig. 1. The interesting thing is that in case of low temperatures $250.95 \leq$ $\leq \mathrm{T} \leq 264.75 \mathrm{~K}$ (at pressure $3.44 \mathrm{MPa}$ ) and $250.55 \leq \mathrm{T} \leq 264.15$ $\mathrm{K}$ (at pressure $6.89 \mathrm{MPa}$ ) the deviations of the ideal gas model from experimental values are lower than values coming from the other models, including GERG model PR EoS, see Fig. 1. Very good results for the area of low temperatures are achieved in the ideal gas model thanks to the equation used for the calculation of the saturated water vapor pressure according to ANSI S1.26-1995. The differences among experimental and calculated figures of the ideal gas model are caused mainly by the fact that the model counts with the water itself (based on saturated water vapor pressure) that means with the pure water vapor without any interaction with other gases and also it does not consider the vapor solubility in the liquid phase of water. It is clear that, by using the ideal gas model the identical results of calculation of the maximal water content in the gas would be reached not only for methane-water but for any gas-water system. On the other hand, even the ideal gas model is more conservative - it gives lower maximal water content in the gas than it should be in the reality - it is an efficient tool for the quick engineering calculations.

On the contrary, no knowledge of limits of the ideal gas model and the equation used for the calculation of the saturated water vapor pressure according to ANSI S1.26-1995 can lead to the false analysis of gas pipeline system and useless or excessive usage of technologies such as gas heating, inhibitors dosage, gas dehydration (primary in the field of gas upstream and NG reservoirs), etc.

Despite the small exceptions, the standard PR EoS model is not satisfactory in comparison with the experimental data because in most cases the calculated maximal water content in methanewater system is much higher than the amount that can be kept by the gas in the reality.

In standard PR EoS and 'Chapoy' modification, water is handled by assuming binary interaction parameter $k_{i j}$ of the order of 0.5 . This assumption can underestimate the solubility of water in NG and give a completely incorrect picture about vapor-liquid equilibrium as we can see when we compare different PR EoS and its modifications.

Thank to the application of new energy term $\alpha\left(T_{r}\right)$ with new three adjustable parameters correlated as a functions of the acentric factor, 'Chapoy' modification of PR EoS gives much more better results than the standard PR EoS model. In comparison with the experimental data the calculated maximal water content is higher in most cases. As Fig. 1 show, major deviations from experimental values are in the scale of temperatures $250.55 \leq T \leq 279.15 \mathrm{~K}$ (pressure 6.89 MPa), which are not characteristics for the area of liquid-vapour but for the zone of hydrate formation for which the equation is not proposed.
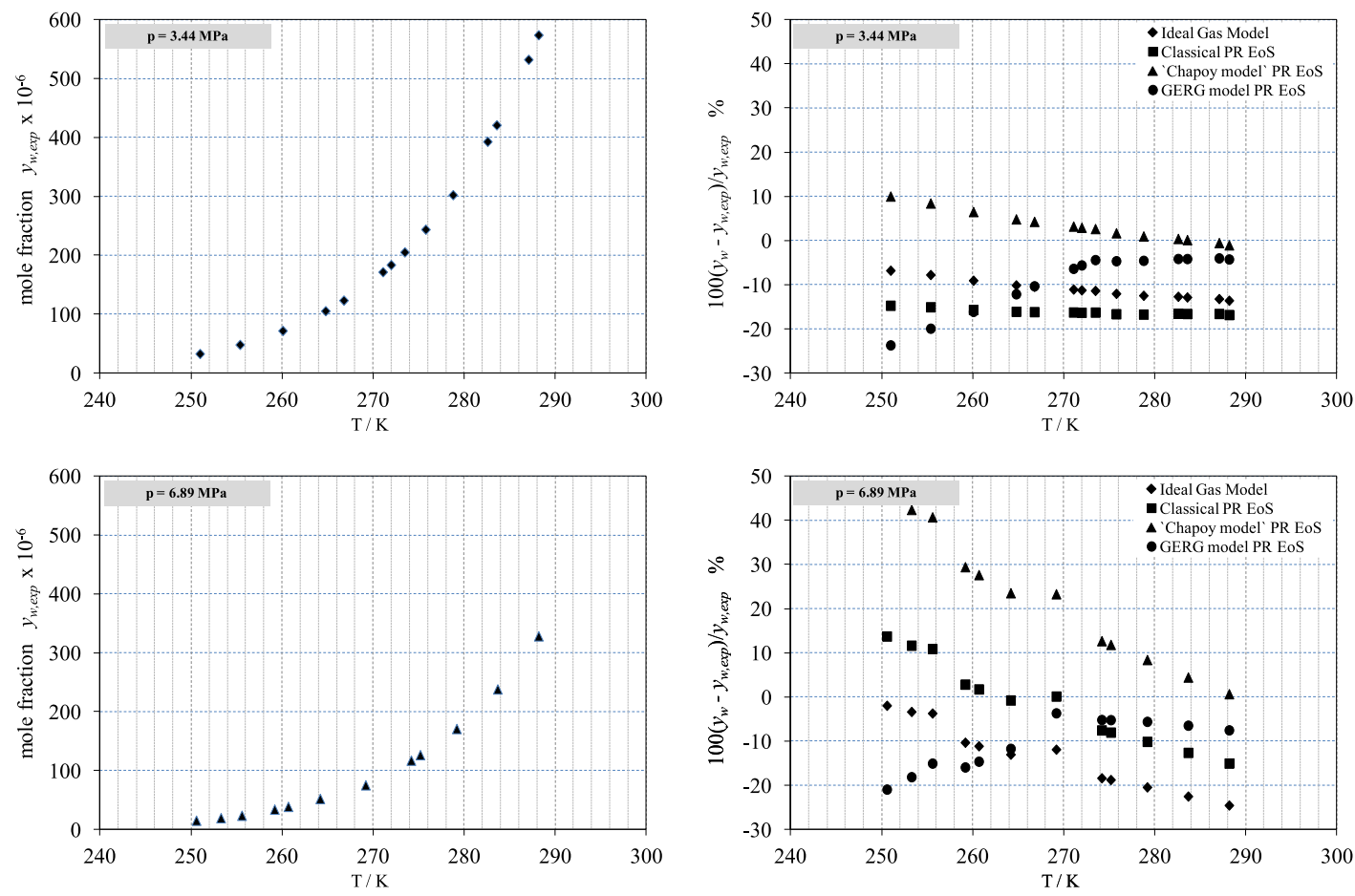

Fig. 1 Experimental water content in the vapor phase of the methane-water and comparison of selected methods with experimental data [12] at pressures 3.44 MPa and 6.89 $\mathrm{MPa}$ 
The presented modification of PR EoS (GERG model) gives in the comparison with the experimental data the best results from all mentioned models. As Figures show, the exception is in the presented scale of low temperatures $250.95 \leq T \leq 264.75 \mathrm{~K}$ (at pressure $3.44 \mathrm{MPa}$ ) and $250.55 \leq T \leq 264.15 \mathrm{~K}$ (at pressure 6.89 $\mathrm{MPa}$ ), where the better results can be obtained from the ideal gas model with equation used for the calculation of the saturated water vapour pressure according to ANSI S1.26-1995. The highest deviations by using modified PR EoS (GERG model) are in case of zone of hydrate formation, that means the temperature ranges $250.95 \leq$ $\leq T \leq 279.15 \mathrm{~K}$ (pressure $3.44 \mathrm{MPa}$ ) and $250.55 \leq T \leq 279.15 \mathrm{~K}$ (pressure $6.89 \mathrm{MPa}$ ), see Fig. 1. E.g. at temperature $250.95 \mathrm{~K}$ (pressure $3.44 \mathrm{MPa}$ ) the deviation from the experimental data is $-23.75 \%$, on the contrary at temperature $283.15 \mathrm{~K}$ the deviation is $0.25 \%$.

Very high deviations from experimental values are in selected range of temperatures and pressures for all NG, see Fig. 1 and Table 2. The selected ranges of temperatures and pressures are showed due to the application of presented PR EoS (GERG model) for calculation especially for the critical parts of pressure reduction valve (valve seats) and pipelines where the temperatures go below 273.15 K. Deviations from experimental data increase with complesity of NG. Originally, GERG model was proposed for VLE applications but for (ice, hydrate)-vapor equilibria was extrapolated PR EoS by fitting binary interaction coefficient (temperature dependent) of PR EoS to experimental data and by using different function for the energy term $\alpha\left(T_{r}\right)$, [13]. However, as it is evident from Fig. 1 and Table 2, these actions for PR EoS are not sufficient and some improvement should be proposed for another modification of PR EoS or by using three different types of phase equilibria and models to cover the actual temperature and pressure ranges (vapor-liquid, vapor-ice, vapor-hydrate).

Water content calculations in the vapor phase using modified PR EoS (GERG model) for various NG (see Table 1), and pressure range $0.5 \leq p \leq 7.0 \mathrm{MPa}$ and temperature range $233.15 \leq$ $T \leq 313.15 \mathrm{~K}$ are presented in Fig. 2. The calculated data shows that the maximal water content decreases with the decreasing temperature and rising pressure. As it is clear from presented results, the ability of NG to keep certain amount of water depends on its component. E.g. a calculation shows that Russian NG (NG n ${ }^{\circ}$ ) is able to keep less humidity than $100 \%$ methane. In contrary as Fig. 2 shows, Norwegian NG-type L can contain more water in gas phase by $2.11 \%$. The maximum water content for water dew point temperature $-7{ }^{\circ} \mathrm{C}$ and pressure $3.92 \mathrm{MPa}$ varied for analyzed NG, e.g. for $100 \%$ methane is 101.372 ppm (mol), Russian NG have $100.960 \mathrm{ppm}$ (mol), for Norwegian NG-type H and type L is $101.439 \mathrm{ppm}(\mathrm{mol})$ and $102.091 \mathrm{ppm}(\mathrm{mol})$ respectively. But in general, the calculations using modified PR EoS (GERG model) show that the ability to contain the water between analyzed NG varies from $-1.62 \%$ to $2.11 \%$, see Fig. 2 .

To draw the final conclusions for future applications of the modified PR EoS (GERG model) in the Slovak gas distribution system, the results from Fig. 1, Table 2 and Fig. 2 should be checked with other experimental data in the future analyses together with
Experimental and calculated water content

Table 2 (mole fractions) of the various NG-water systems by using PR EoS (GERG-model)

\begin{tabular}{|c|c|c|c|c|c|c|}
\hline \multicolumn{5}{|c|}{ Experimental data } & \multicolumn{2}{|c|}{$\begin{array}{l}\text { Calculations Peng- } \\
\text { Robinson EoS } \\
\text { (GERG-model) }\end{array}$} \\
\hline \multirow[t]{2}{*}{$\mathrm{NG} \mathrm{n}^{\circ}$} & $T$ & $p$ & Data & $\begin{array}{l}y_{w, e x p} \\
\times 10^{6}\end{array}$ & $y_{w, \text { calc }} \times$ & error \\
\hline & $\mathrm{K}$ & $\mathrm{MPa}$ & & $\mathrm{mol}$ & $\mathrm{mol}$ & $\%$ \\
\hline 1 & 250.95 & 3.440 & [12] & 32.300 & 24.628 & -23.75 \\
\hline 1 & 255.35 & 3.440 & [12] & 47.700 & 38.175 & -19.97 \\
\hline 1 & 260.05 & 3.440 & [12] & 71.400 & 59.866 & -16.15 \\
\hline 1 & 264.75 & 3.440 & [12] & 105.000 & 92.215 & -12.18 \\
\hline 1 & 266.75 & 3.440 & [12] & 123.000 & 110.247 & -10.37 \\
\hline 1 & 271.05 & 3.440 & {$[12]$} & 171.200 & 160.218 & -6.41 \\
\hline 1 & 271.95 & 3.440 & [12] & 183.300 & 172.960 & -5.64 \\
\hline 1 & 250.55 & 6.890 & [12] & 14.800 & 11.693 & -20.99 \\
\hline 1 & 253.25 & 6.890 & [12] & 19.000 & 15.546 & -18.18 \\
\hline 1 & 255.55 & 6.890 & {$[12]$} & 23.200 & 19.698 & -15.10 \\
\hline 1 & 259.15 & 6.890 & {$[12]$} & 33.600 & 28.233 & -15.97 \\
\hline 1 & 260.65 & 6.890 & [12] & 38.300 & 32.683 & -14.67 \\
\hline 1 & 264.15 & 6.890 & [12] & 51.700 & 45.621 & -11.76 \\
\hline 1 & 269.15 & 6.890 & [12] & 74.900 & 72.116 & -3.72 \\
\hline 2 & 268.15 & 1.020 & [11] & 4.514 & 4.053 & -10.21 \\
\hline 2 & 273.09 & 1.063 & [11] & 6.857 & 5.874 & -14.34 \\
\hline 2 & 278.15 & 1.007 & [11] & 8.884 & 8.875 & -0.10 \\
\hline 2 & 283.14 & 1.018 & [11] & 13.715 & 12.341 & -10.02 \\
\hline 2 & 28 & 1.012 & [11] & 17.925 & 17.234 & -3.86 \\
\hline 2 & 288.15 & 6.017 & [11] & 3.460 & 3.223 & -6.86 \\
\hline 3 & 250.92 & 0.491 & [13] & 120.000 & 169.918 & 41.60 \\
\hline 3 & 256.64 & 1.000 & [13] & 120.000 & 144.383 & 20.32 \\
\hline 3 & 260.07 & 1.490 & [13] & 120.000 & 132.973 & 10.81 \\
\hline 3 & 264.15 & 2.011 & [13] & 120.000 & 141.863 & 18.22 \\
\hline 3 & 266.87 & 2.509 & [13] & 120.000 & 143.945 & 19.95 \\
\hline 3 & 269.04 & 2.994 & [13] & 120.000 & 144.981 & 20.82 \\
\hline 3 & \begin{tabular}{|l}
255.37 \\
\end{tabular} & 0.477 & [13] & 210.000 & 268.432 & 27.82 \\
\hline 3 & 261.80 & 0.998 & [13] & 210.000 & 232.088 & 10.52 \\
\hline 3 & 266.92 & 1.557 & [13] & 210.000 & 233.279 & 11.09 \\
\hline 3 & 269.42 & 2.025 & [13] & 210.000 & 221.855 & 5.65 \\
\hline 3 & 256.53 & 0.498 & [13] & 310.000 & 286.769 & -7.49 \\
\hline 3 & 263.15 & 0.968 & [13] & 310.000 & 269.890 & -12.94 \\
\hline 3 & 268.11 & 1.536 & [13] & 310.000 & 261.834 & -15.54 \\
\hline 3 & 270.54 & 1.991 & [13] & 310.000 & 247.899 & -20.03 \\
\hline 4 & 263.15 & 1.500 & [14] & 159.700 & 175.413 & 9.84 \\
\hline 4 & 263.15 & 6.000 & [14] & 50.600 & 43.347 & -14.33 \\
\hline 4 & 273.15 & 1.500 & [14] & 365.100 & 410.979 & 12.57 \\
\hline 4 & 273.15 & 4.000 & [14] & 129.700 & 154.799 & 19.35 \\
\hline 4 & 273.15 & 6.000 & [14] & 102.100 & 102.539 & 0.43 \\
\hline 4 & 283.15 & 6.000 & [14] & 226.300 & 207.474 & -8.32 \\
\hline
\end{tabular}



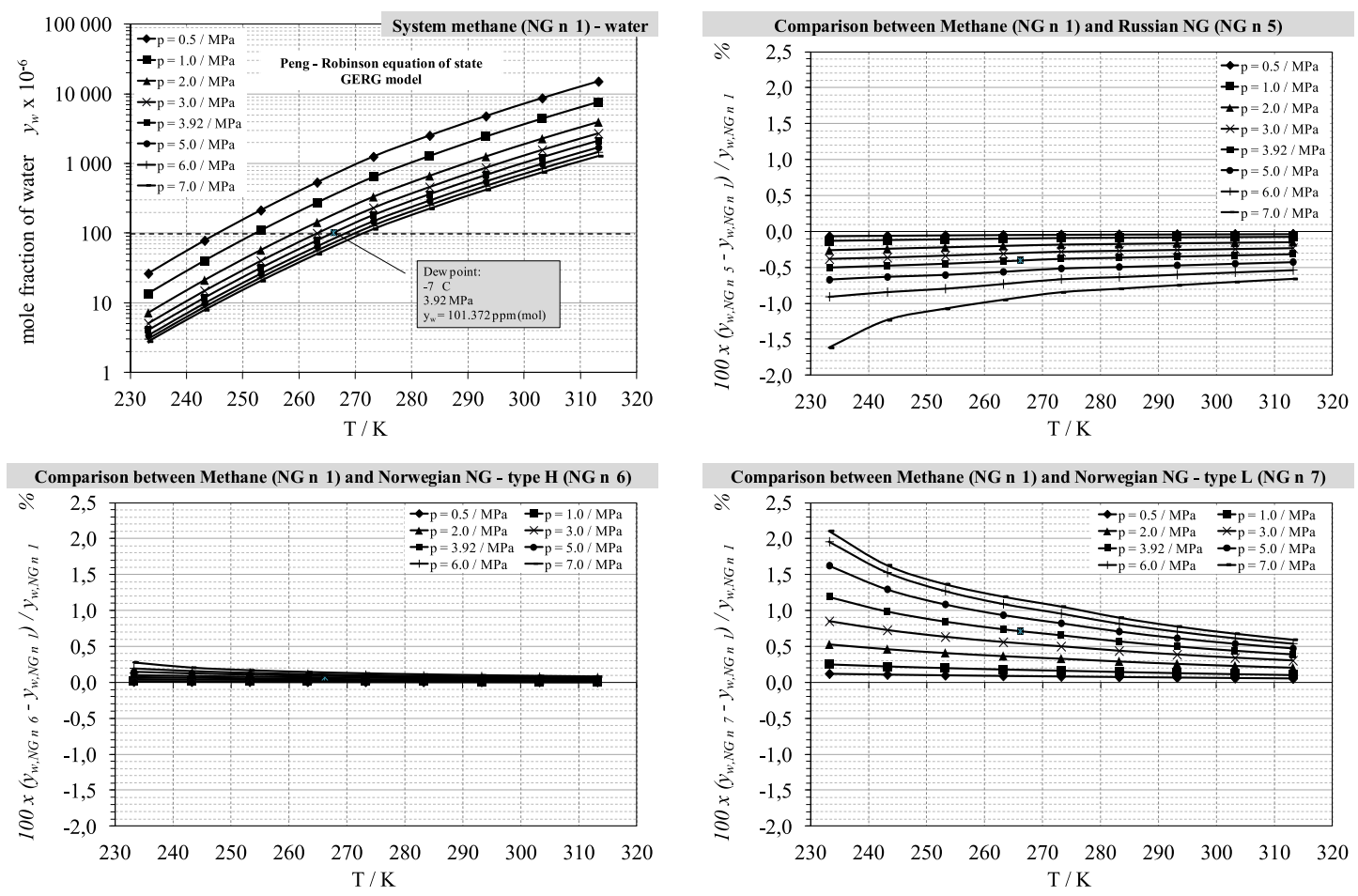

Fig. 2 Water content calculations of the methane $\left(N G n^{\circ} 1\right)$ - water and $N G n^{\circ} 5,6,7$ - water systems and comparison between them from maximum water content point of view by using modified PR EoS (GERG model)

the model in order to make the necessary improvements and to achieve the scope to have an accurate computational tool for the calculations of the gas maximum water content in the critical parts of the gas distribution system.

As it is clear from the experimental data and results of various PR EoS with modifications and for selected NG, binary interaction parameter $k_{i j}$ (between various components of the NG) and energy temperature dependent term $\alpha\left(T_{r}\right)$ for various components of NG highly influence the results of the water content calculation in the system gas-water. Acceptable agreement was achieved between the experimental and calculated results by using modified PR EoS (GERG model), but various areas of improvements should be applied. The classical approach can be in more precisious correlations of binary interaction parameter $k_{i j}$ and energy term $\alpha\left(T_{r}\right)$ based on experimental data for various temperature ranges. Today trends are based on using CPA (Cubic Plus Association) method, for futher readings see [10]. CPA combines the classical simple PR EoS with an advances association term. Associating systems are those which contain compounds capable of hydrogen bonding (e.g. water or some inhibitors for gas hydrate prevention, etc.). The scope is to describe better the dense phases (i.e. the gas phase or the liquid water phase) coupled a solid phase model, which can be an ice or hydrate model.

\section{Conclusion}

The presented PR EoS (GERG-model) will be in the next work after necessary modifications applied in the Slovak gas distribution dispatching system implemented into the SCADA (Supervisory Control and Data System). The goal is to optimize energy requirement for NG heating before its throttling into gas pressure reduction stations. So, it's necessary to identify crucial stations for dew point (or maximum water content) measurement and recalculate these data for other groups of stations where such measurement is not performed. In case of the Slovak Republic we are speaking about 1700 crucial selected pressure reduction stations with basic splitting by nominal pressures PN 65, PN 40 and PN 25.

\section{Acknowledgement}

I would like to thank to non-investment fund EkoFond, n. f. (www.ekofond.sk) for the financial support of project 563/PG04/ 2011: Reduction of energy consumption at gas pipeline system by application of new hydrate models. 


\section{References}

[1] KNIZAT, B., TOTH, P., RAJZINGER, J., GOLHA, M., SALAJ, M.: Numericke riesenie a citlivostna analyza vonkajsich faktorov na parametre plynarenskych sieti [Numerical Solution and Sensitivity Analysis of External Factors on Parameters of Natural Gas Pipeline Network]. Vyskumna sprava ulohy 40/98, STU, Strojnicka fakulta, Bratislava, 2001

[2] SLOAN, E. D., KOH, C. A.: Clathrate Hydrates of Natural Gases. $3^{\text {rd }}$ edition. New York : CRC Press, 2008, ISBN-10: 0471661740

[3] JANDACKA, J., MALCHO, M.: Unasanie pevnych castic prudiacim plynom v plynovodoch [Adrifting of Solid Particles by Flowing Gas in Natural Gas Pipelines]. Slovgas. 2007, XXII, No. 6, pp. 22-24

[4] MICUCCI, L.: Technology of Choice. Discusses a New Method of Natural Conditioning for Long Pipeline Transportation. Hydrocarbon Eng., vol. 15, No. 10, 2010, pp. 67-70

[5] MASARYK, M.: Vypoctove a experimentalne overenie zmesi chladiv R12/R134a v malych chladiacich zariadeniach [Numerical and Experimental Verification of R12/R134a Cooling Fluids in Small Refrigeration Devices]. PhD Thesis, Slovak University of Technology in Bratislava, Bratislava, 1994

[6] SANDLER, S. I.: Chemical, Biochemical, and Engineering Thermodynamics - $4^{\text {th }}$ edition, New York : John Wiley \& Sons, 2006, ISBN-10: 0471661740

[7] ZUCKERWAR, A. J.: Handook of the Speed of Sound in Real Gases, vol. III, Speed of Sound in Air. New York : Academic Press, 2002, ISBN: 0-12-782513-4

[8] EDMISTER, W. C., LEE, B. I.: Applied Hydrocarbon Thermodynamics, vol. 1 - 2nd edition. Houston : Gulf Professional Publishing, 1984, ISBN: 0-87201-855-5

[9] ISO 18453:2004: Natural Gas - Correlation between Water Content and Water Dew Point: The International Organization for Standardization, July 2004

[10] KONTOGEORGIS, G. M., FOLAS, G. K.: Thermodynamic Models for Industrial Applications. From Classical and Advanced Mixing Rules to Association Theories, John Wiley \& Sons, 2010, ISBN: 978-0-470-69726-9

[11] CHAPOY, A.: Etude des Equilibres des Systems: Eau-Hydrocarburez-Gaz Acides dans le cadre de la production de Gaz. PhD. Thesis, Paris : Ecole des Mines de Paris, 2010

[12] CHAPOY, A., HAIGHIGHI, H., BURGASS, R., TOHIDI, B.: Gas Hydrates in Low Water Content Gases. Experimental Measurement and Modeling Using the CPA Equation of State. Fluid Phase Equilibria 296, 2010, pp. 9-14, ISSN: 0378-3812

[13] BLANCO. S. T., AVILA. S., VELASCO. I., RAUZY. E., OTIN. S.: Dew Points of Ternary Methane + Eethane + Butane and Quaternary Methane + Ethane + Butane + Water Mixtures: Measurement and Correlation. Fluid Phase Equilibria 171, 2000, pp. $233-242$. ISSN: 0378-3812

[14] FOLAS. G. K., FROYNA. E. W., LOVLAND. J., KONTOGEORGIS. G. M., SOLBRAA. E.: Data and Prediction of Water Content of High Pressure Nitrogen, Methane and Natural Gas. Fluid Phase Equilibria 252, 2007, pp. 162-174. ISSN: 0378-3812. 